\title{
Análise da flutuação das populações de aedes aegypti e aedes albopictus em uma escola de Cuiabá-MT
}

\author{
Thomas Eduardo Schiffino de Oliveira', Carlo Ralph de Musis² \\ ' Universidade Federal de Mato Grosso, Cuiabá, MT, Brasil \\ ${ }^{2}$ Universidade de Cuiabá, Cuiabá, MT, Brasil
}

\section{Resumo}

O aumento expressivo da população de Cuiabá desencadeou um crescimento desordenado da cidade, acompanhado de uma infraestrutura e saneamento básico deficientes, estabelecendo assim condições favoráveis à proliferação dos vetores da Dengue (Aedes aegypti) e Febre Amarela (Aedes albopictus) na região, sendo esses dotados de grande poder de adaptação aos ambientes habitados pelo homem. Tendo isso em vista, o objetivo deste trabalho foi analisar a influência de fatores microclimáticos na flutuação das populações de mosquitos Aedes aegypti e Aedes albopictus em uma escola da periferia de Cuiabá entre janeiro e agosto de 2012, fazendo uso do modelo diferenciado de armadilha de oviposição (ovitrampa). A coleta dos dados bióticos (número de ovos) foi feita na escola André Avelino Ribeiro em intervalos de quinze dias. Os resultados indicaram que a precipitação foi o único fator microclimático a influenciar a proliferação do vetor da dengue na escola. Foram verificadas diferenças significativas para o número de ovos coletados na estação chuvosa em relação a estação seca. No entanto, observou-se valores expressivos para o número de ovos nesta estação, indicando que mesmo no período de seca a incidência da espécie pode ser elevada. Além disso, os altos índices de densidade de ovos e vetorial, assim como de positividade da ovitrampa observados na escola revelaram que o local configura-se como um polo de proliferação e disseminação da espécie Aedes aegypti.

Palavras-chave: Aedes aegypti, bioestatística, ovitrampa, biometeorologia, fatores abióticos.

\begin{abstract}
The expressive increase of the population of Cuiabá unleashed a disorderly growth of the city, accompanied by a deficient infrastructure and basic sanitation, thus establishing favorable conditions for the proliferation of vectors of dengue (Aedes aegypti) and yellow fever (Aedes albopictus) in the region, and these endowed great power of adaptation to environments inhabited by humans. Keeping this in view, the aim of this work was to analyze the influence of microclimatic factors in the fluctuations of the populations of Aedes aegypti and Aedes albopictus in a school of the periphery of Cuiabá between January and August 2012, making use of the differentiated model of oviposition trap (ovitrap). The collection of the biotic data (number of eggs) was made in school André Avelino Ribeiro at intervals of fifteen days and the abiotic data: air temperature, relative humidity and rainfall been obtained by means of weather station of the National Institute for Space Research. The results indicated that precipitation was the only microclimatic factor at influencing the proliferation of the dengue vector in school. Significant differences were found for the number of eggs collected in the rainy season in relation to the dry season. However, it was observed expressive values for the number of eggs in this season, indicating that even in the dry period the incidence of the species may be high. Furthermore, the high indices of egg density and vector, as well as of positivity of the ovitrap observed in school have revealed that the place configures itself as a pole of proliferation and dissemination of specie Aedes aegypti.
\end{abstract}

Keywords: Aedes aegypti, biostatistics, ovitrap, biometeorology, abiotic factors. 


\section{INTRODUÇÃO}

A dengue é caracterizada como uma doença típica de áreas tropicais e subtropicais, sendo causada por vírus e transmitida pelos mosquitos Aedes aegypti, no Brasil e em outros países do continente americano, e Aedes albopictus, na Ásia, geralmente de forma epidêmica.

Todavia, cada vez mais são noticiados casos de doenças oriundas do vetor da dengue e da febre amarela urbana - o Aedes aegypti - não só em países de clima tropical e subtropical como também em regiões onde não haveria condições favoráveis para a proliferação da espécie e, por conseguinte, das arboviroses.

Diante disso tem-se atualmente que cerca de dois quintos da população mundial estão sujeitos a contaminação pelo vírus da dengue. Estimativas apontam que pode haver, a cada ano, 50 milhões de casos de infecção em todo o mundo. Além disso, há países em que a incidência de focos (criadouros para reprodução) de mosquitos alcança patamares seis vezes maior que o aceitável, considerando a existência de condições mínimas de saneamento básico e infraestrutura.

Dentre os países de clima favorável à proliferação do vetor da dengue e outras arboviroses, o Brasil destaca-se, também, em função de sua extensão territorial com microclimatologia diversificada, saneamento básico deficiente e densidade populacional urbana alta e desorganizada. O que torna necessário estudar a adaptação desse vetor a cada um desses ambientes.

Nesse sentido, um dos primeiros estudos realizados no país a relacionar fatores ambientais com o comportamento dos mosquitos Aedes aegypti data de 1908 e já revelava uma estreita relação entre os fatores bióticos, abióticos e a proliferação dessa espécie na região Sudeste.

$\mathrm{Na}$ região centro-oeste o destaque é o estado de Mato Grosso, onde há riscos constantes, sempre que se inicia o período chuvoso, de surtos epidêmicos de doenças relacionadas ao vetor Aedes aegypti, principalmente a dengue. E onde pesquisas de monitoramento dessa e de outras espécies do gênero só passaram a ser realizadas nas últimas décadas. De modo geral as maiores incidências de focos e consequentes ocorrências de casos dessa doença situam-se nas regiões periféricas dos grandes centros e em municípios onde não há planejamento urbano.

Em todo estado de Mato Grosso, por exemplo, no ano de 2011, foram mais de três mil notificações, sendo dezesseis registros da forma agravada da doença, além de três óbitos. Na capital - Cuiabá - o índice de infestação de mosquitos Aedes aegypti, em média, foi de 4,8\%, enquanto o recomendado pela Fundação Nacional de Saúde (FUNASA) é 1\%. Ou seja, Cuiabá enfrentou uma infestação 380\% superior ao estabelecido pelos órgãos competentes.

Estudos das interações entre a atmosfera e a biosfera no que tange às influências de fatores bióticos e abióticos na flutuação das populações de mosquitos Aedes aegypti e Aedes albopictus em um determinado local são altamente relevantes, uma vez que a compreensão dessas influências pode contribuir não só para o controle dessas populações como, também, para o estabelecimento de um modelo preditivo de surtos eficiente, tanto do vetor como da doença.

No entanto, apesar de serem diversos os trabalhos que buscam associar fatores bióticos e abioticos à proliferação dessas espécies de mosquitos, estes apresentam resultados baseando-se, muitas vezes, totalmente em dados de terceiros, desconsiderando as suas naturezas. Outros trabalhos, por sua vez, se equivocam ao não considerar o comportamento microclimático da área estudada, sendo este de extrema importância para a compreensão das suas influências sobre a proliferação de mosquitos Ae. aegypti e albopictus. Em tais estudos busca-se associar a proliferação da espécie, ou mesmo sua disseminação, com dados meteorológicos de estações localizadas em regiões com microclima diferente do local pesquisado.

Além disso, o monitoramento feito atualmente pelo Governo Federal se baseia em pesquisa larvária - tipo de pesquisa que nos últimos anos vem se mostrando ineficaz, além de implicar em altos custos operacionais.

A relevância dessa questão reside no fato de as fêmeas de Ae. aegypti e albopictus não oviporem, isto é, depositarem seus ovos, em qualquer lugar. Para que as fêmeas façam a oviposição em certo local, este deve atender à determinadas condições ambientais, indo além da simples presença de água parada. Ou seja, não é somente a presença de água parada que fará com que ele se torne um criadouro, mas, antes de tudo, o estabelecimento de uma cadeia de fatores físicos e biológicos que tornam este local proprício ao desenvolvimento dos ovos do mosquito.

Por outro lado, os mosquitos do gênero Aedes, em especial as espécies Ae. aegypti e Ae. albo- 
pictus, são dotados de grande poder adaptativo, sendo o primeiro considerado altamente domiciliar e tendo preferência por locais de elevada concentração populacional. O segundo, por sua vez, possui habitos oportunistas agindo tanto em áreas urbanas como rurais. O que transforma, também, espaços públicos como escolas, creches, hospitais, praças, comércio etc., em pontos de circulação viral e vetorial.

Desse modo o objetivo deste trabalho foi analisar a influência de fatores ambientais abióticos na flutuação das populações de mosquitos Ae. aegypti e Ae. albopictus em uma escola do bairro Morada da Serra, região periférica de Cuiabá - MT, no período entre janeiro e agosto de 2012, fazendo uso de um modelo diferenciado de armadilha de oviposição (Ovitrampa) e com metodologia que considera as variações microclimáticas do local onde a pesquisa foi realizada. Para o cumprimento de tal objetivo foi necessário: analisar as condições ambientais e microclimáticas do local pesquisado; analisar o comportamento e influência da temperatura do ar, da umidade relativa do ar e da precipitação acumulada na flutuação das populações de mosquitos Ae. aegypti e albopictus; realizar análise do índice de positividade (IPO), índice de densidade de ovos (IDO) e índice de densidade vetorial (IDV) das ovitrampas instaladas; efetuar análise espacial e temporal da flutuação de mosquitos no local, comparando os resultados dos períodos chuvoso e seco; e realizar análise estatística dos dados bióticos e abióticos obtidos.

\section{BIOMETEOROLOGIA APLICADA À ENTOMOLOGIA E EPIDEMIOLOGIA}

Os fenômenos climáticos influenciam os processos biológicos em diversas escalas temporais. Sendo assim, pode-se considerar a biometeorologia um campo científico interdisciplinar responsável pelo estudo das interações entre a atmosfera e a biosfera, tendo como escala de tempo as estações do ano ou intervalos menores. Nesse sentido ela se contrasta com a Bioclimatologia.

Segundo a ISB (International Society of Biometeorology) (1970) apud Gonçalves (2012, p. 6)2,

Biometeorologia é o estudo dos efeitos diretos e indiretos (de natureza irregular, flutuante ou rítmica) de físico-, químico- , físico-químico-, micro- e macro-ambientes, de ambas, atmosfera da Terra e outros ambientes similares extraterrestres, nos sistemas físico-químico em geral e nos organismos vivos em particular (plantas, animais e seres humanos).

De modo geral, os estudos envolvendo trocas de energia entre a superfície e a atmosfera são importantes por caracterizar o microclima local e por identificar as relações entre as mesmas. Além disso, permite conhecer as possíveis variações do tempo e do microclima da região, bem como identificar as prováveis alterações do ambiente local gerado pela ação antropogênica (CURADO, 2011).

Para Carvalho (1986) in Rodrigues (2004, p. 1), os estudos destinados a esclarecer o papel que os fatores ambientais desempenham sobre a população de insetos são de grande interesse, pois a nocividade destes depende justamente de sua abundância. De modo que esta ação implica em como os fatores do meio podem condicionar a proliferação dos insetos, controlando suas populações para que não alcancem quantidades máximas que variam de acordo com seus potenciais bióticos.

No que tange, especificamente, ao estudo das interrelações entre os fatores do clima e as espécies Ae. aegypti e Ae. albopictus têm-se que estas são, ainda, amplamente investigadas. Por exemplo, as condições ambientais como temperaturas e umidades altas favoreceram a proliferação dos mosquitos em questão no município de Uruguaiana-RS (SOUZA et al., 2008). Concomitantemente, em Giruá-RS, períodos úmidos com precipitações frequentes e temperaturas amenas contribuiram para a prolifração do vetor da dengue.

No estado de São Paulo, por outro lado, verificou-se que quanto menor a temperatura mais lento foi o processo de infestação por Ae. aegypti, onde esse fator agiu preponderantemente na expansão geográfica dessa espécie na região. No entanto, não se observou influência significativa dos índices pluviométricos na expansão do mosquito.

"Em geral em áreas com baixa umidade verifica-se uma redução significante na oviposição das fêmeas de Ae. aegypti" (CANYON et al., 1999, p. 963, tradução nossa). Entretanto, populações de uma mesma espécie, estabelecidas em regiões geográficas distintas, em países de clima tropical e subtropical com grandes variações de temperatura e umidade, apresentam variações consideráveis em sua capacidade reprodutiva (SOTA; MOGI, 1992a, b; MOGI et al., 1996 apud ACIOLI, 2006, p. 19)3. 
No campo epidemiológico, de acordo com Rouquayrol (2003), o clima é o aspecto do ambiente físico que tem, até agora, concentrado maior atenção para estudos epidemiológicos. Estudam-se os fatores climáticos, para que, através deles, possam ser inferidas hipóteses de causalidade quanto a algum fator de risco cuja variação na natureza dependa da variação de agum fator climático.

Em consequência disso, cada vez mais estudos apontam que as condições microclimáticas favorecem a ação dos vetores.

Beserra e Castro Jr. (2008) observaram que populações de Ae. aegypti provenientes de quatro diferentes regiões bioclimáticas do estado da Paraíba apresentaram padrões diferenciados de crescimento, desenvolvimento e potencial biótico resultantes das adaptações às condições ambientais próprias de cada região.

De forma análoga, Wolfarth (2011) observou que fatores climáticos contribuiram para a proliferação dos casos de malária em diversas localidades da região Amazônica, de modo que ações contra doenças dessa natureza devem considerar as características intrínsecas de cada região estudada.

Rouquayrol (2003) destaca, também, que os fatores climáticos que mais proximamente influenciam as biocenoses, i.e., os seres vivos implicados nos processos de transmissão de abroviroses são a temperatura e a umidade relativa do ar e a precipitação pluviométrica.

\section{MATERIAL E MÉTODO}

\section{I ESTAÇÃO METEOROLÓGICA}

Os dados abióticos de temperatura, umidade e precipitação foram coletados entre janeiro e agosto de 2012, fazendo uso da estação meteorológica do Instituto Nacional de Pesquisas Espaciais (INPE), modelo Weather Link Vantage Pro 2, estando localizada a 1,9km do local da pesquisa. Os dados obtidos foram coletados em intervalos de cinco minutos, sendo feitas, posteriormente, as médias para a temperatura e umidade relativa e a soma (acumulado) para a chuva, referentes aos períodos analisados na pesquisa.

Um aspecto que deve ser considerado nos estudos da influência da temperatura sobre a população de mosquitos é a análise individualizada das temperaturas máximas e mínimas, visto que essa análise pode induzir a interpretações equivocadas dos dados. Por esse motivo não foram feitas, neste trabalho, análises sobre as temperaturas máximas e mínimas, mas sim uma avaliação conjunta das temperaturas por meio da amplitude térmica.

\subsection{MODELO DIFERENCIADO DE OVITRAMPA}

A armadilha de oviposição proposta foi desenvolvida a partir de materiais recicláveis e de fácil obtenção, de modo que quando comparada com a pesquisa larvária ou mesmo com outros modelos de ovitrampa, fica evidente a sua eficiência e praticidade, além de uma ótima relação custo-benefício.

As ovitrampas utilizadas consistem de garrafas PET (Politereftalato de etileno), verdes, de 21 com $10 \mathrm{~cm}$ de altura na qual era adicionada uma solução com $270 \mathrm{ml}$ de água não tratada, $30 \mathrm{ml}$ de infusão de gramíneas (Cynodon dactylon (L., 1805)), além de dois grãos de arroz, triturados. Em cada recipiente foi aplicada uma camada de tinta da cor preto fosco na parte externa. Como área para oviposição usou-se tecido em algodão cru com as seguintes dimensões: $32,5 \mathrm{~cm}$ de comprimento por $8,5 \mathrm{~cm}$ de largura. O furo para fixação do fio de náilon foi feito $2 \mathrm{~cm}$ abaixo da borda superior.

\subsection{LOCALIZAÇÃO E CARACTERIZAÇÃo DA ÁREA EXPERIMENTAL}

O local onde a pesquisa foi desenvolvida compreende uma área de $11,2 \mathrm{~km}^{2}$ situando-se no bairro Morada da Serra (CPA I), região periférica da capital, Cuiabá, com coordenadas $\left(15^{\circ} 33^{\prime} 22^{\prime \prime}\right.$, $\left.56^{\circ} 03^{\prime} 09^{\prime \prime} \mathrm{W}\right)$. Em tal área funciona a escola estadual André Avelino Ribeiro (Figura 8), que atende a população não só da localidade como também de outros bairros e cidades, tendo 1952 alunos matriculados no ano de 2012.

A região em questão é caracterizada por espaços de grande urbanização e aglomeração populacional, aliados a espaços de matas fechadas, parques florestais e lagoas. Aliado a isso tem-se o fato de terem sido encontrados focos de mosquitos e potenciais criadouros no local. O que pode tornar este, um polo de disseminação dos vetores da dengue e febre amarela urbana e silvestre. Além disso, ao 
longo de todo período de coleta foram encontrados resíduos sólidos, principalmente copos descartáveis, garrafas PET e latas de tinta destampadas jogados em diversos pontos da escola.

Ao todo determinou-se nove pontos estratégicos (PE) onde as ovitrampas foram instaladas, tendo estes sido determinados em função de se mostrarem como criadouros em potencial das espécies estudadas.

\subsection{COLETA E TRATAMENTO DAS AMOSTRAS}

As coletas em campo foram realizadas em um período de 15 semanas epidemiológicas consecutivas entre janeiro e agosto de 2012. Todas as amostras recolhidas foram devidamente acondicionadas e conduzidas ao Laboratório de Entomológica Médica da Universidade Federal de Mato Grosso (UFMT). Os procedimentos para instalação e coleta das armadilhas seguiram a metodologia proposta por Fay e Eliason (1966). Após cada coleta e tratamento das amostras foi feita a contagem dos ovos em laboratório por meio do microscópio estereoscópico (lupa) com um aumento de 40x.

Quanto à identificação da espécie, sua confirmação foi feita por meio dos mosquitos adultos, utilizando-se a chave de Consoli e Oliveira (1994), após eclosão espontânea dos ovos em laboratório. Para tanto, foram analisados três caracteres morfológicos das duas espécies de mosquitos: mesonoto (para a identificação da espécie) e antena e palpo maxilar (para identificação do sexo).

\section{5 ÍNDICES DA ARMADILHA DE OVIPOSIÇÃO}

Uma vez realizadas as contagens dos ovos foram utilizados os seguintes índices relacionados à ovitrampa para análise da distribuição espacial e temporal do vetor no local, sendo eles:

Índice de Positividade da Ovitrampa

$$
I P O=\frac{\text { armadilhas positivas }}{\text { armadilhas examinadas }} \times 100
$$

Equação 1

Índice de Densidade de Ovos

$$
I D O=\frac{n^{0} \text { de ovos }}{\text { armadilhas positivas }}
$$

Índice de Densidade Vetorial

$$
I D V=\frac{n^{\mathrm{o}} \text { de ovos }}{\text { armadilhas examinadas }}
$$

Através destes índices, segundo Gomes (1998 e 2002), é possível conhecer a flutuação vetorial da espécie na área estudada, o nível de infestação e a taxa de reprodução das fêmeas em diferentes períodos. 


\subsection{ANÁLISE ESTATÍSTICA}

Todo o processo de modelagem foi desenvolvido com o suporte do software SPSS 20.0, os procedimentos orientaram-se por dois eixos:

Inicialmente com estatística descritiva, principalmente gráficos de médias e intervalos de confiança por bootstrap, com a intenção de caracterizar o comportamento geral das das variáveis estudadas. -Whitney.

Comparação da oviposição mediana entre as estações seca e chuvosa pelo teste U de Mann-

Na sequencia foi executada um procedimento de análise de agrupamentos, utilizando a distância euclidiana quadrática e o método de Ward, para a definição de grupos de pontos de coleta, conforme a recorrência da oviposição observada.

\section{RESULTADOS}

A presença de ovos foi detectada em todas as coletas, assim como em todos os pontos pesquisados. Entre estes, se destacam os pontos 06, do dia 12 de março, e 08, do dia 16 de julho, com 331 e 293 ovos, respectivamente (Tabela 2). Todavia, o valor máximo foi obtido no ponto 01 , no qual 440 ovos foram encontrados em uma única armadilha na coleta do dia 26 de março. Em contraponto, os menores valores não-nulos verificados foram 1 e 2 ovos, respectivamente, dos dias 30 de julho e 13 de agosto.

Os índices gerados a partir da ovitrampa indicaram alto nível de infestação da área estudada, com valores máximos e mínimos de IPO, IDO e IDV iguais a: 88,9\% e 11,1\%; 192,3 ovos/arm. pos. e 35,2 ovos/arm. pos. e 106,8 ovos/arm. exam. e 10,8 ovos/arm. exam., nessa ordem (Figuras 1 e 2).

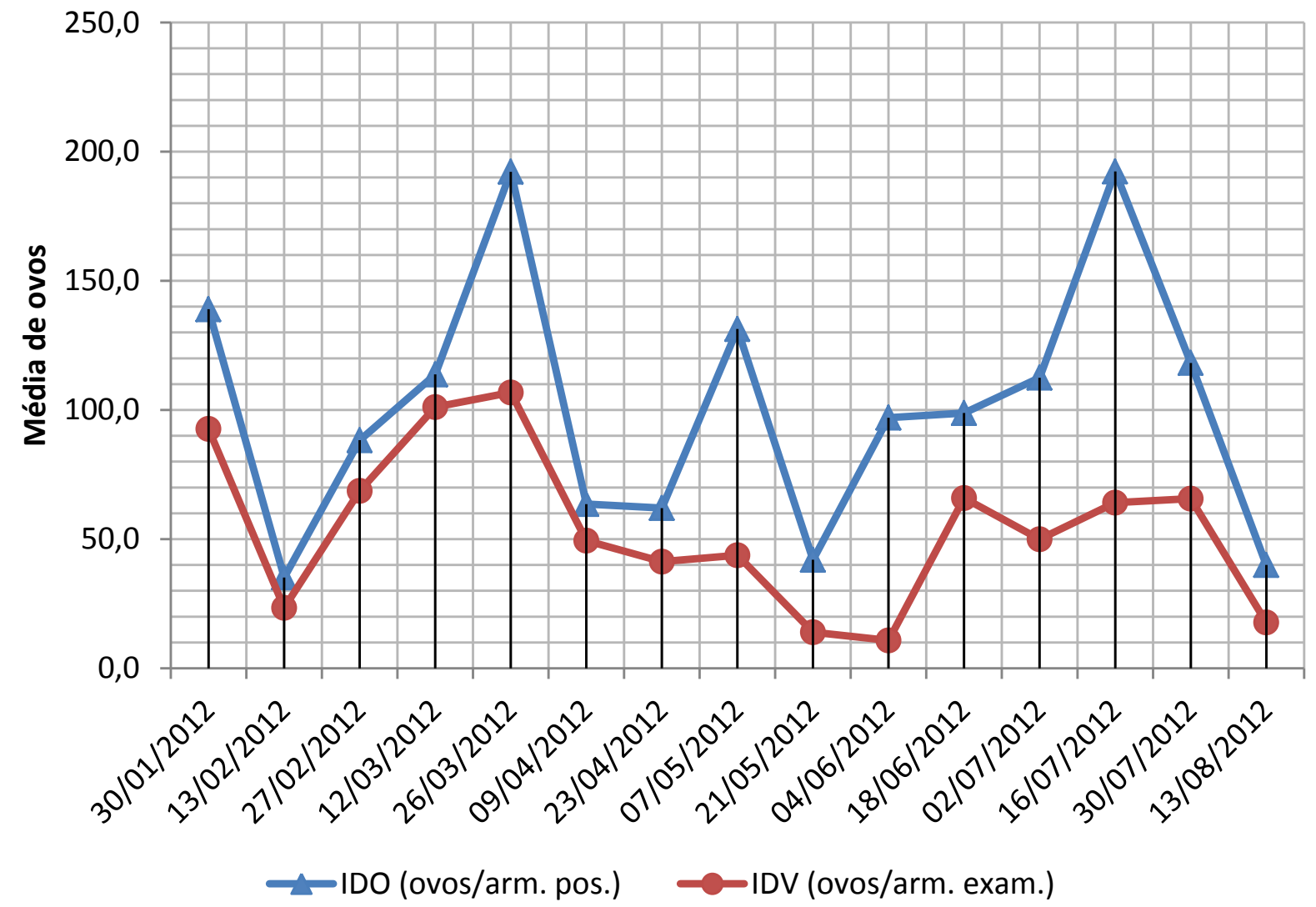

Figura 1 - Variação temporal da média de ovos por armadilha positiva e examinada. 
Na Figura 1 é possível observar que tanto a densidade de ovos (IDO) como a vetorial (IDV) apresentaram baixos valores nas coletas dos dias 13 de fevereiro e 13 de agosto, indicando uma menor ocorrência de fêmeas do mosquito no local, nestas datas.

O número de ovos, por coleta, revelou variações expressivas ao longo do período de estudo, tendo apresentado grande amplitude de acordo com os seguintes valores de máximo e mínimo: 961 ovos e 97 ovos, respectivamente (Figura 2).

As Figuras 1 e 2, quando analisadas conjuntamente, permitem identificar características do comportamento das espécies na escola, de modo que percebe-se que no decorrer das quinze semanas epidemiológicas monitoradas os meses de março e abril foram os que apresentaram as menores variações em relação aos demais.

Todavia, todos os índices - IPO, IDO e IDV - variaram não somente nesse período como ao longo de todo estudo, demosntrando uma concentração de ovos do mosquito em torno de pontos estratégicos específicos.

Além disso, na primeira quinzena de fevereiro e segunda do mês de maio foi feita na escola a limpeza do terreno antes tomado por vegetação. Desse modo, observando tais períodos na Figura 2, nota-se que estes apresentaram valores discrepantes dos demais pontos próximos. O que parece indicar uma relação direta entre as condições ambientais do local e a proliferação das espécies estudadas. Do ponto de vista entomológico tal afirmação é plausível, uma vez que com a limpeza do terreno as condições de favorecimento à reprodução do mosquito foram alteradas. Tal afirmação é corroborada por Oliveira et al. (2006), que verificou que ao se eliminar resíduos sólidos (potenciais criadouros do mosquito) de quintais no distrito rural de Uberlândia - MG, houve uma redução considerável do número de ovos encontrados nas ovitrampas.

De acordo com Costa et al. (2007) os índices obtidos das ovitrampas podem apontar as seguintes fases, no que tange ao monitoramento do Aedes: CONTROLE, quando a densidade do vetor não proporciona risco de transmissão de dengue em moldes epidêmicos, observado se IPO $\leq 40 \%$, IDO $\leq 40$

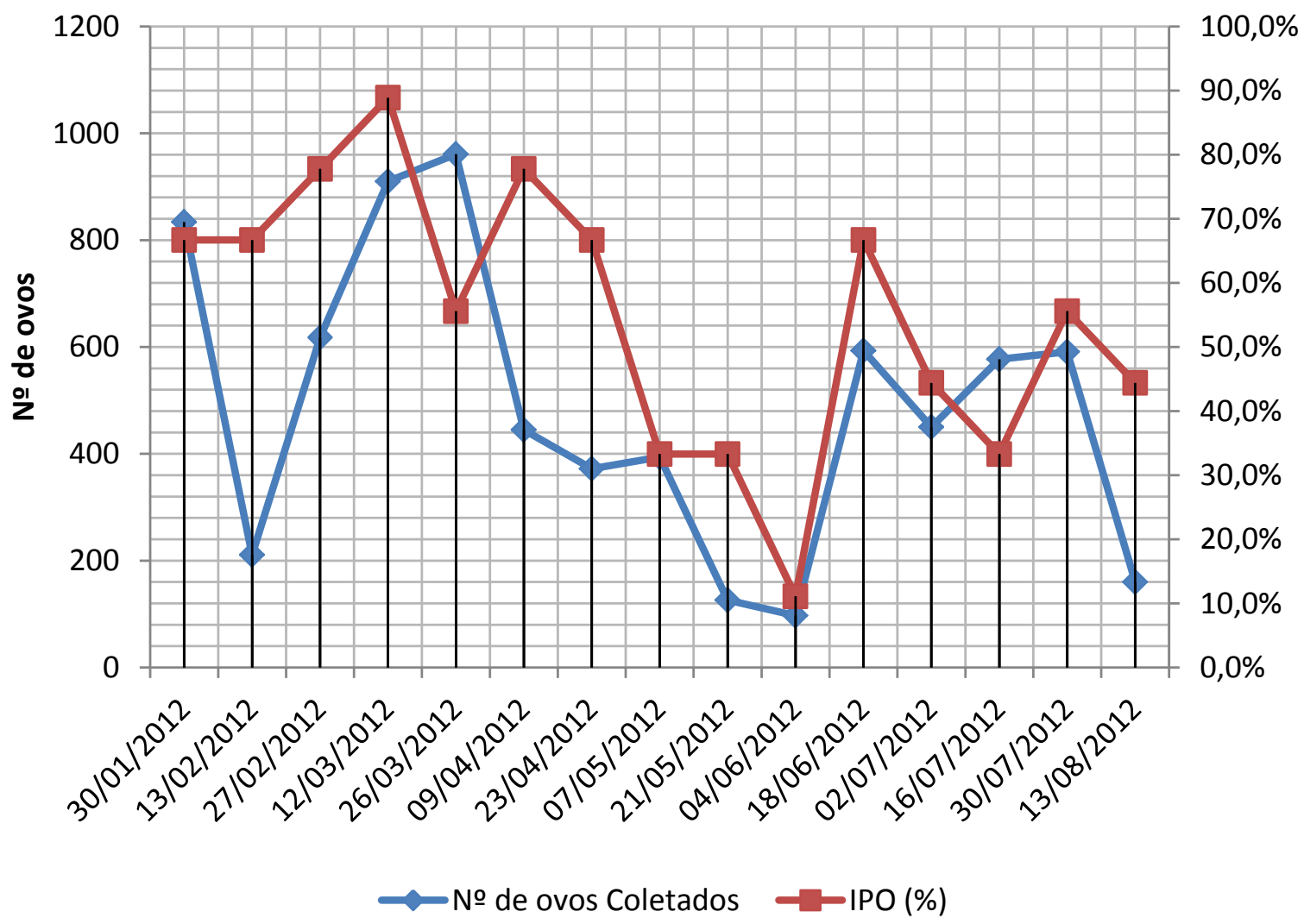

Figura 2 - Variação temporal do $\mathrm{n}^{\circ}$ de ovos e IPO, de acordo com as coletas realizadas. 


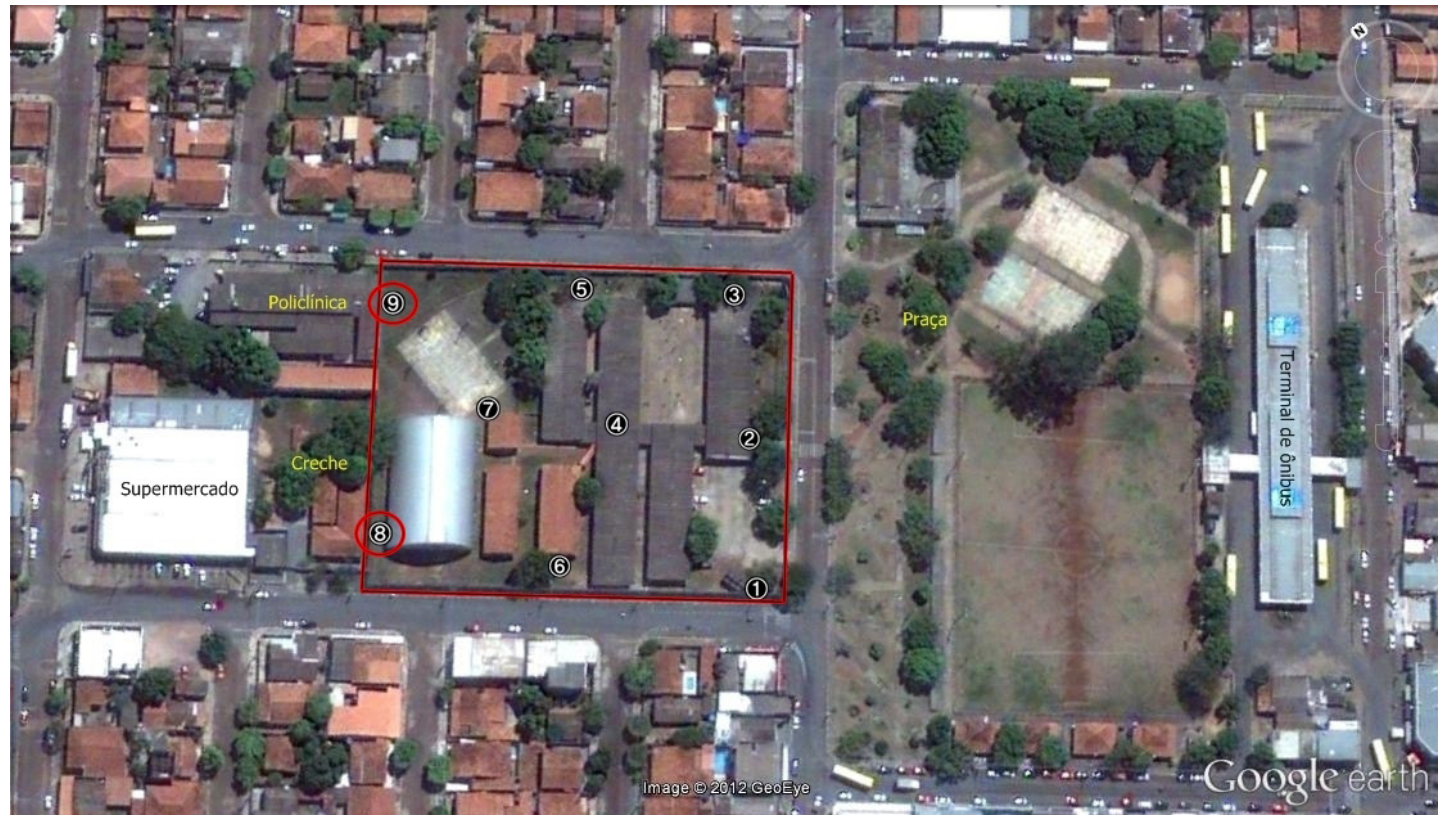

Figura 3 - Mapa da escola com os pontos estratégicos onde foram detectados Ae. albopictus, em destaque. Fonte: Google EarthTM.

ovos e IDV $\leq 20$ ovos; ALERTA, quando se observa o aumento das áreas infestadas, ou seja, IPO variando de 41 a $60 \%$, IDO de 41 a 60 ovos e IDV de 21 a 40 ovos; e RISCO, quando a densidade vetorial elevada proporciona o aumento de casos de dengue em áreas com circulação viral, observado quando IPO $>60 \%$, IDO $>60$ ovos e IDV $>40$ ovos.

Dessa forma, observando as Figuras 1 e 2, é possível verificar que a área de estudo permaneceu durante os meses de janeiro a maio, junho e julho, em estado de risco quanto à possibilidade de epidemias de dengue e outras arboviroses. Apenas nas coletas dos dias 21/05, 04/06 e 13/08 observou-se a fase de controle do mosquito. A coleta do dia 13/02 foi a única a apresentar a fase de alerta.

Nesse sentido, uma discussão que cabe ser salientada refere-se aos pontos estratégicos onde foram encontrados ovos de mosquitos Ae. albopictus.

Nos oito meses de coleta foram verificadas ocorrências dessa espécie em três delas: uma em 13/02, onde encontrou-se 8 ovos no ponto 09 ; uma em 23/04, com 18 ovos no ponto 08 e, novamente nesse ponto, 40 ovos no dia 21/05.

Observando as Figuras 3 e 4 percebe-se que os pontos 08 e 09, mesmo próximos aos demais,

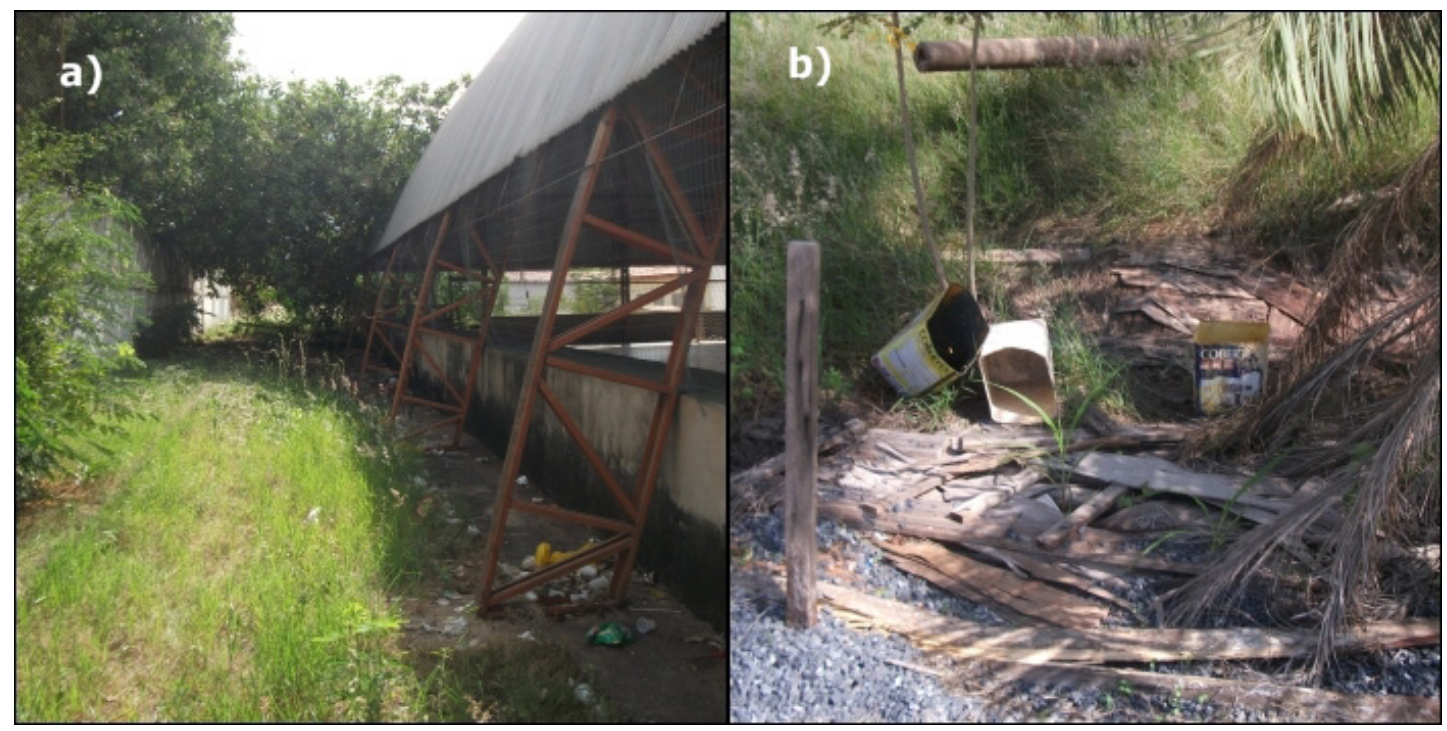

Figura 4 - Locais onde foi detectada presença de Ae. albopictus: a) PE 08, b) PE 09. 
diferem destes claramente, pois apresentam, entre outros aspectos: mata densa e sombreada e amplos espaços para oviposição pelas fêmeas, com o mínimo de interferências. Tais aspectos condizem justamente com o comportamento do Ae. albopictus que, ao contrário do Ae. aegypti, possui hábitos silvestres, tendo preferências, também, por áreas urbanas com cobertura vegetal densa. No estado de São Paulo, por exemplo, tem sido comum o encontro de Ae. albopictus associado a Ae. aegypti em criadouros artificiais (MARQUES et al., s.d.).

Por outro lado é perceptivel o risco que a presença dessa espécie no local representa, mesmo ocorrendo em um nível tão baixo. Sua reprodução nessa escola revela que a fêmea encontrou nos pontos em questão condições favoráveis à sobrevivência e desenvolvimento de seus ovos, visto que as fêmeas de mosquitos Aedes em geral, segundo o microbiologista prof. Maulori Cabral (2011), consideram antes de ovipor diversos fatores bióticos e abióticos do pontencial criadouro.

\section{CONSIDERAÇÕES FINAIS}

O monitoramento e controle das populações de Ae. aegypti e Ae. albopictus configura-se com uma eficiente e viável técnica de controle de endemias e epidemias relacionadas à essas espécies. Para tanto o conhecimento das interrelações entre as espécies e o meio ambiente é fundamental. Objetivou-se, desse modo, analisar as influências de variáveis microclimáticas na flutuação das populações de mosquitos vetores da dengue e febre amarela em uma escola da capital.

Sendo assim, de acordo com os resultados obtidos pode-se fazer as seguintes considerações:

Relevancia do modelo de ovitrampa usado, como metodo de controle de mosquitos

Relevancia da presença do vetor nas escolas (citar o $\mathrm{n}^{\circ}$ de escolas de cuiaba; falar da vizinhaça da escola (creche, policlinica et.)

Presença de albopictus no local

Periodo chuvoso $\mathrm{X}$ seco (incidencia de $\mathrm{n}^{\circ}$ alto de ovos na seca)

$\mathrm{PE}$ com maior densidade de ovos

Interrelações entre o clima e a proliferação da especie.

\section{REFERÊNCIAS}

CONSOLI, R. A. G. B.; OLIVEIRA, R. L. Principais Mosquitos de Importância Sanitária no Brasil. $1^{\text {a }}$ edição. Rio de Janeiro: Fiocruz, 1994. $1^{a}$ reimpressão, 1998. 228 p.

FAY, R. W.; ELIASON, D. A. A Preferred Oviposition Sites as a Surveilance Method for Aedes aegypti. Mosquito News 26: $531-535,1966$.

MIYASAKI, R. D. et al. Monitoramento do Mosquito Aedes aegypti (Linnaeus, 1762) (Diptera: Culicidae), por Meio de Ovitrampas no Campus da Universidade Federal de Mato Grosso, Cuiabá, Estado de Mato Grosso. Revista da Sociedade Brasileira de Medicina Tropical, Uberaba, vol. 42, nº 4, julho/agosto de 2009. 